\title{
Decentralized Coordination Power Control for Islanding Microgrid Based on PV/BES-VSG
}

\author{
Meiqin Mao, Cheng Qian, and Yong Ding
}

\begin{abstract}
Virtual synchronous generator (VSG) technology for integration of distributed energy resources attracts increasing attentions for its enabling inverters to simulate the inertia and damping characteristics of synchronous generators and improve the stability of the system. In this paper, a decentralized VSG-based adaptive coordinated control strategy is proposed for islanding microgrids consisting of photovoltaic generators combined with battery energy storages in DC side (PV/BES-VSG). By the proposed method, the droop characteristics of VSGs can be adaptively adjusted according to the DC bus voltage. In this way, the local controllers of PV/BES-VSG units can switch operating modes automatically without the need of a central controller, so that the power sharing among PV/BES-VSG units is allocated according to the maximum output power of PVs and the limit of charging/discharging power of BES instead of merely rated capacity of the inverters. To test the proposed method, an islanding model of microgrid with two PV/BES-VSG units in parallel is built in Matlab/Simulink. The simulation results show that by the proposed control strategy, the coordination control between PV and BES, and between PV/BESVSG units can be effectively realized with maximum use of PV power under the premise of the rational distribution of power.
\end{abstract}

Index Terms-Decentralized coordination control, power sharing, PV/BES-VSG unit, virtual synchronous generator.

\section{INTRODUCTION}

A $\mathrm{S}$ one of renewable energy sources (RESs), photovoltaic (PV) generation system has been booming during last decades all over the world for its important role in solving global energy crisis and environmental problems [1], [2]. Specifically in China, by the end of 2017, the total installation of PV sreaches 130.25 GW [3], ranked the first top globally. And according to the report from IEA [1], by 2040 solar power will be the single largest source of low-carbon electricity generation, with all renewable generations accounting for $40 \%$ of the total electricity production. But, most of installed PVs are generally connected to the power system or microgrids through inverters, which provide much faster control than traditional power systems because of the application of power electronic devices and PWM control methods [4].Therefore,the total inertia of the whole power system, especially of microgrids decreases greatly with the increas-

\footnotetext{
Manuscript received February 27, 2018. This work was supported in part by National Natural Science Foundation of China under Grant 51577047 and in part by Foreign Science and Technology Cooperation Project of Anhui Province under Grant 1604b0602015.

The authors are with the Research Center for Photovoltaic System Engineering, MOE, Tunxi Road 193, School of Electrical Engineering and Automation, Hefei University of Technology, Hefei 230009, China (e-mail: mmqmail@163. com; qchfut@163.com; yong dsyuct@163.com).

Digital Object Identifier 10.24295/CPSSTPEA.2018.00002
}

ing penetration of PVs, leading frequency becomes sensitive to the fluctuations in loads and renewable energy systems, and posing a great challenge to stable operation of power system [5].

To address the problem aforementioned, the concept of Virtual Synchronous Generator (VSG) is presented, by which, an inverter can be controlled to behave as traditional synchronous generator and provide enough or desired inertia for the power system [6]-[8] so that the dynamic performances of the system can be enhanced. So far, the developments of VSG for microgrids are focused on enhancing system stability [9], [10], distributed control of converters [11] for power system and power sharing in microgrids [12].

In the typical VSG systems above, battery energy storages or PV panels are used as primary energy sources for the inverters [13]. The corresponding control method may be grouped into two categories: centralized control and decentralized control. In the centralized control methods, a central energy management system (EMS) is required [14], [15], which relies on the communications between units and a central controller and may reduce the system reliability.

To reduce the reliance on communications, decentralized coordination control without communication has attracted wide attentions [16]. The droop control method without communication is usually used to realize the power sharing and energy management in the microgrid with multiple hybrid PV and battery energy storage systems. But according to the relationship between total PV power available, BES charging/discharging power limits, SOC levels and load demands, there will be a variety of operation modes. This feature of the micrgrids brings great challenges to the design of individual local controllers. In current proposed methods, each local controller in the microgrid identifies the current operation mode with accessing to local information, through a state machine method [17], or via microgrid AC bus frequency [18], [19]. In the reference [17] the control strategy mainly focuses on the power flow management between hybrid PV/BES unit and microgrid, the coordinated control of the DC-DC converters at DC side are not discussed in details. In [18], AC frequency is used to reflect Battery SOC condition, while the PV generation regulates its output power based on measured frequency to keep the frequency stable. The control strategy in [19] relies on battery energy to regulate the AC-bus frequency, the local controllers determine the operation state of each unit by the corresponding power relationship, and generate logic signals for switching operation mode. Switching error of operation mode at any unit will result in the operation failure of the microgrid. Therefore, more adaptive decentralized control methods are expected to address issues above [20], [21].

In this paper, the VSG-based inverter, together with the 
combined PV and battery energy storages (BES) hybrid unit at DC side, is defined as a PV/BES-VSG unit. And decentralized adaptive coordinated control strategy is proposed for islanding microgrid with multiple PV/BES-VSG units to keep the frequency and voltage stable meanwhile taking the most advantage of PVs. With the proposed method, the droop characteristics of VSGs can be adaptively adjusted according to the DC link voltage, and local controller for each PV/Battery-VSG unit obtains the information about the available PV power, the battery SOC, the output power of the inverter of its own unit and the microgrid frequency to switch operating states automatically. An islanded microgrid model with two PV/BES-VSG units is built in Matlab/Simulink to verify the effectiveness of the proposed control strategy.

The rest of the paper is arranged as follows. The structure and operation states of microgrid are described in Section II. The proposed control strategy is discussed in Section III. Typical operating modes analysis for PV/BES-VSG is discussed in Section IV. In Section V, the proposed method is verified by simulations in Matlab/Simulink considering various operating conditions, followed by conclusions in Section VI.

\section{II.Structure of Microgrid with Multiple PV/BES-VSGs}

\section{A. Structure of the Microgrid}

The structure of the microgrid investigated in this paper is depicted in Fig. 1. It consists of multiple PV/BES-VSG units. Each PV/BES-VSG unit contains a PV subsystem, a BES subsystem and a VSG-controlled inverter. PV subsystem includes PV array and a boost DC-DC converter. BES subsystem includes batteries and a bidirectional dc/dc converter. The PV unit and the BES unit are both connected to the DC side. The inverter adopts VSG control to supply the required power for the local loads which are represented as $Z_{\text {Load }}$.

\section{B. Operating Mode Analysis of Microgrid}

For the microgrid with PV/BES-VSG units shown in Fig. 1, the power flow coordination control to maintain the power balance of such a microgrid is required from three aspects:

1) Power flow management between different PV/BES-VSG units;

2) Power flow management among PV, BES and output power of the inverter in each PV/BES-VSG unit;

3) Power flow management between PV and BES in each hybrid PV/BES-VSG unit.

In practice, for the case 3 ), to avoid depleting the battery prematurely, battery should either stay idle or be charged when surplus power becomes available, that is, battery supplies power only when all other PV generations reach their upper limits. For the case 1) and 2), PV available power, battery conditions and the load demands should all be taken into consideration to optimize load sharing.

Considering the discussions above and depending on max-

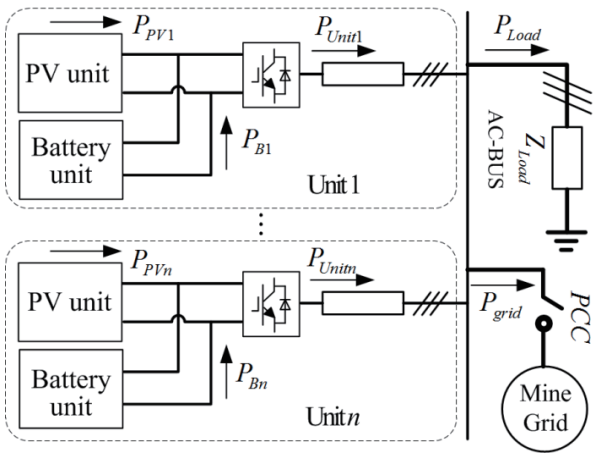

Fig. 1. Structure diagram of the researched microgrid.

imum output PV power available, charging power ratings of the batteries and the load demands, the operation states of the microgrid can be grouped in four main states as follows.

State I: The total PV maximum power is larger than the sum of the total battery charging power limits and loads, as shown in (1).

$$
\sum_{i=1}^{n} P_{P V_{-} M P P T i}>\sum_{i=1}^{n}\left|P_{c h \_l i m i}\right|+P_{\text {Load }}
$$

where, $P_{P V \text { MPPTi }}$ is PV maximum power available (under standard test condition, $P_{P V M P P T i}$ is equal to its peak power $\left.P_{P V} p\right)$; $P_{c h \_l i m i}$ is battery charging power; $P_{\text {Load }}$ is the load power.

With the condition of (1), if each VSG is assumed to share load demands with the PV operating at maximum power point (MPP), the load power sharing coefficient $\eta_{i}$ for $i^{\text {th }}$ PV/BESVSG unit can be described as in (2).

$$
\eta_{i}=P_{P V_{-} M P P T i} / \sum_{i=1}^{n} P_{P V_{-} M P P T i}
$$

But in this case, for each PV/BES-VSG unit, there are two possible operating states, as shown in (3) and (4), respectively.

$$
\begin{aligned}
& \forall i \leq n, P_{P_{-} M P P T i}>\left|P_{c h \_l i m i}\right|+\eta_{i} P_{\text {Load }} \\
& \exists i \leq n, P_{P_{-} \text {MPPTi }}<\left|P_{c h \_l i m i}\right|+\eta_{i} P_{\text {Load }}
\end{aligned}
$$

In the case shown by (3), all PV generation units can produce enough power to balance the loads by sharing coefficient in (2), leading PV curtailment necessary in all PV units, and all batteries can be charged with maximum power. Meanwhile, in the case shown by (4), the maximum power of PV from the $i^{\text {th }} \mathrm{PV} / \mathrm{BES}-\mathrm{VSG}$ unit is not high enough to share the loads by the power sharing coefficient in (2) with accommodating the charging demand of its battery. In other words, if it still shares load power according to $\eta_{i}$, the battery charging power for $i^{\text {th }} \mathrm{PV} / \mathrm{BES}-\mathrm{VSG}$ unit needs to be reduced. However, for the whole microgrid, the maximum utilization of PV generation is not realized. Therefore, the inverter of the unit meeting in (4) has to enter in PCM (Power Controlled Mode), its output power is controlled shown as in (5).

$$
P_{U n i t i}=P_{P V_{-} M P P T i}-\left|P_{c h-l i m i}\right|
$$


In this way, all batteries are charged with maximum power to maximize use of PV power while curtailment of PV output power should be performed in some units to keep power balance, with rest PV units operating at MPP.

State II: The total PV maximum power is less than the sum of the total battery charging power limits and load demands, but is larger than the load demands, as shown in (6).

$$
\left\{\begin{array}{l}
\sum_{i=1}^{n} P_{P V_{-} M P P T i}<\sum_{i=1}^{n}\left|P_{c h \_l i m i}\right|+P_{L o a d} \\
\sum_{i=1}^{n} P_{P V_{-} M P P T i}>P_{\text {Load }}
\end{array}\right.
$$

With the condition of (6), all PV units operate at MPP, the batteries absorb the surplus power, and the battery charging power is related to its corresponding SOC and power rating, the load power sharing coefficient $\lambda_{i}$ is presented as in (7).

$$
\lambda_{i}=\left|P_{c h \_l i m i}\right| / \sum_{i=1}^{n}\left|P_{c h \_l i m i}\right|
$$

Then, the output power of each inverter is shown in (8). It is worthy to note that the inverter output power may be negative, that means, some units with less PV power will get the power from others with more PV power.

$$
P_{U n i t i}=P_{P V_{-} M P P T i}-\lambda_{i}\left(\sum_{i=1}^{n} P_{P V_{-} M P P T i}-P_{\text {Load }}\right)
$$

State III: The load is larger than the total PV maximum power, but is less than the sum of the total discharging power limits of battery and the total PV maximum power, as shown in (9).

$$
\left\{\begin{array}{l}
\sum_{i=1}^{n} P_{P V_{-} M P P T i}<P_{\text {Load }} \\
\sum_{i=1}^{n} P_{P V_{-} \text {MPPTi }}+\sum_{i=1}^{n}\left|P_{\text {disch_lim } i}\right|>P_{\text {Load }}
\end{array}\right.
$$

where, $P_{\text {disch lim }}$ is battery discharging power.

With the condition of (9), all PV units operate at MPP, the batteries will be discharged to keep power balance, and their discharging power are related to their corresponding SOC and power rating, the power sharing coefficient $\xi_{i}$ is presented as in (10).

$$
\xi_{i}=P_{\text {disch_lim } i} / \sum_{i=1}^{n} P_{\text {disch_lim } i}
$$

Then, the output power of each inverter unit is controlled as shown in (11).

$$
P_{\text {Uniti }}=P_{P V_{-} M P P T i}+\xi_{i}\left(P_{\text {Load }}-\sum P_{P V_{-} M P P T i}\right)
$$

\begin{tabular}{|c|c|c|c|c|}
\hline $\begin{array}{l}\text { MG Operating } \\
\text { State }\end{array}$ & $\begin{array}{c}\text { PV/BES- } \\
\text { VSG Unit } \\
\text { Operating } \\
\text { State }\end{array}$ & $P_{P V i}$ & $P_{B i}$ & $P_{\text {Uniti }}$ \\
\hline I & 1 & $P_{c h \_ \text {Limi }}+\eta_{i} P_{\text {Load }}$ & $P_{c h \_ \text {limi }}$ & $\eta_{i} P_{\text {Load }}$ \\
\hline I & 2 & $P_{P V-M P P T i}$ & $P_{c h \_ \text {lim } i}$ & (5) \\
\hline II & 3 & $P_{P V M P P T i}$ & $\lambda_{i}\left(\sum P_{P V M P P T_{i}}-P_{\text {Load }}\right)$ & (8) \\
\hline III & 4 & $P_{P V M P P T i}$ & $\xi_{i}\left(\sum P_{P V M P P T i}-P_{\text {Load }}\right)$ & (11) \\
\hline IV & 5 & $P_{P V \_M P P T i}$ & $P_{\text {disch_limi }}$ & (13) \\
\hline
\end{tabular}

State IV: The total load is larger than the sum of the total PVmaximum power and the total battery discharging power limits, as shown in (12).
TABLE I

Power Distribution For EAch Unit

Note: Roman and Arabic numerals are used to distinguish the operating states of microgrid and PV/BES-VSG unit, respectively.

$$
\sum_{i=1}^{n} P_{P V_{-} M P P T i}+\sum_{i=1}^{n}\left|P_{\text {disch_limi } i}\right|<P_{\text {Load }}
$$

With the condition of (12), the whole microgrid is overloaded,with all PV units operating at MPP and the batteries discharged with the power limits. The inverter enters in PCM, and its output power is controlled as shown in (13). Then, frequency is reduced greatly. This will trigger non-critical load shedding to ensure the continuity and reliability of power supply.

$$
P_{\text {Uniti }}=P_{P V_{-} M P P T i}+P_{\text {disch_lim } i}
$$

To sum up the discussions above, from the view of the whole microgrid, there are four operating states in total, but for each PV/BES-VSG unit, there will be five operating states, as listed in TABLE I.

\section{Control Strategy for Microgrid with PV/BATTERY-VSG UNIT}

\section{A. Proposed Control Strategy}

For the microgrid with PV/BES-VSG units shown in Fig. 1, the operation of each PV/BES-VSG unit can be divided into five states as shown in TABLE I. But both in state 3 and 4, the batteries are used to keep generation or consumption balance. Therefore, the two states can be merged as one state to reduce the design complexity of the controllers. Considering the operation characteristics of microgrid and PV/BES-VSG units, the operation of each PV/BES-VSG unit can be divided into four states.

To achieve the objectives aforementioned, the proposed decentralized coordination control is shown in Fig. 2. The control method consists of three subsystem controller: PV controller, ESS controller and VSG controller.

PV controller: In the PV controller shown in Fig. 2, the hysteresis comparator in the control loop is used to switch the control modes of the PV controller. PV controller collects DClink voltage $v_{d c}$, comparing with reference voltage $v_{d c_{-} P \text { Vref. }}$. If the hysteresis comparator outputs $1, \mathrm{PV}$ operatsat MPP, corresponding to state 2, 3, 4 and 5, as shown in TABLE I. If the hysteresis comparator outputs $0, \mathrm{PV}$ changes into VCM (voltage controlled 


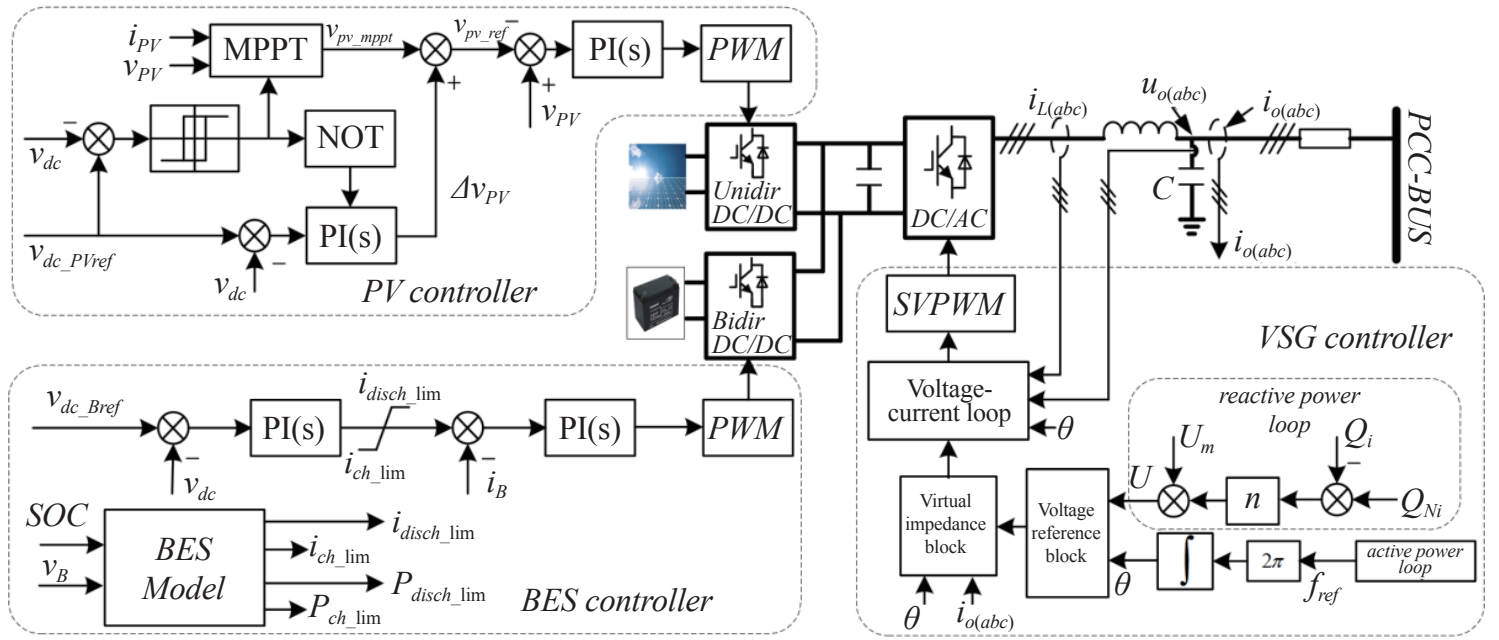

Fig. 2. Control structure of the proposed control strategy.

mode), PV output power is controlled based on output power of inverter and battery charging power, corresponding to state 1 . The outer loop is DC-link voltage loop, regulating DC-link voltage. The inner loop is to control operation voltage of PV array, in which $v_{P V}$ and $i_{P V}$ represent PV array output voltage and PV array output current, respectively.

BES controller: BES (battery energy system) controller adopts voltage and current dual-loop control. The outer voltage loop is DC-link loop, regulating DC-link voltage. The upper and lower output limits of the following PI controller are determined by battery SOC, limiting the charging/discharging current. The inner loop is battery current loop. When the output of DC-link voltage loop reaches saturation, it indicates the battery charging/ discharging current has reached the maximum value, and the current loop will limit actual charging/discharging current to the allowable range through PI controller. Under this situation, the terminal voltage of battery changes slowly, the battery enters into PCM, corresponding to the state 1, 2 and 5 in TABLE I, otherwise, it operates in VCM, corresponding to the state 3 and state 4 .

The function of BES model in Fig. 2 is to obtain the maximum charging/discharging current and power limits based on battery SOC and terminal voltage $v_{B}$, where, $i_{c h \text { lim }}, P_{\text {ch lim }}$ represent maximum charging current and power limits, respectively, and $i_{\text {disch_lim }}, P_{\text {disch_lim }}$ represent maximum discharging current and power limits, respectively. $v_{d c \text { ref }}$ is DC-link voltage reference, $i_{B}$ is battery output current. The detailed BES model is introduced in [22].

VSG controller: With reference to the simplified electrical model of synchronous generator, the swing equation of synchronous generator is added to the power loop of the inverter, and with the energy storage device, a virtual moment of inertia is produced to make it present the characteristics of a synchronous generator. The control block diagram for VSG controlled inverter (referred to as VSG) is shown in Fig. 2. It consists of three loops. The outer-loop is the power loop and contains the $\omega-P$ droop frequency regulation function, and the inner-loop is a typical voltage and current double loops. The drive signals are produced using SVPWM technology. In addition, since the line in low-voltage microgrid has a large resistance-to-inductance ratio, a virtual impedance control loop is introduced to decouple the active and reactive power control of the inverter with VSG and improve the power distribution accuracy between parallel VSGs [23]. This paper mainly focuses on active power sharing, so reactive power control is beyond the scope of this paper.

One of advantages by VSG control technology is that the parameters can be adjusted adaptively based on demands. However, the introduction of swing equation increases the order of the system, which leads that inverter is prone to power oscillation during transient process. Transfer function models for multiple VSG-based inverters are established to analyze dynamic response characteristics of VSGs and the influence of parameters.

$\Delta P_{i}, \Delta P_{\text {refi }}$ are the output power variation and reference power variation of the $i^{\text {th }}$ inverter, respectively. $J_{i}$ and $D_{i}$ are virtual inertia and damping coefficient of the $i^{\text {th }}$ inverter, respectively. $\Delta \omega_{i}$ represents angular frequency variation of the $i^{\text {th }}$ inverter. The small signal model of power control loop can be presented as in (14)

$$
\Delta \omega_{i}=\frac{1}{J_{i} s+D_{i}}\left(\Delta P_{r e f i}-\Delta P_{i}\right)
$$

The output impedance of VSG is designed to be inductive when virtual impedance control is applied, thus, the power transfer equation is

$$
\Delta P_{i}=\frac{3}{2} \frac{E_{i} V}{X_{i}} \cos \delta_{i} \Delta \delta_{i}=k_{i} \Delta \delta_{i}
$$

where, $E_{i}$ is the amplitude of inverter output voltage, $V$ is amplitude of PCC voltage, $\delta_{i}$ is phase difference between inverter and $\mathrm{PCC}$, if the virtual inductance is large enough, the output reactance $X_{i}$ of VSG can be replaced by virtual inductance $X_{i}=\omega L_{v i}$, phase difference variation $\Delta \delta_{i}$ can be obtained as

$$
\Delta \delta_{i}=\frac{1}{S}\left(\Delta \omega_{i}-\Delta \omega\right)
$$

where, $\Delta \omega$ represents angular frequency variation of PCC. 
For the system consisting of multiple inverters, the balanced power flow should satisfy (17) when the load demands change, $\Delta P_{\text {Load }}$ is load power variation

$$
\sum_{i=1}^{m} \Delta P_{i}=\Delta P_{\text {Load }}
$$

Then transfer function model can be obtained based on (14) $\sim(17)$

$$
G_{p l i}=\frac{\Delta P_{i}}{\Delta P_{\text {Load }}}=\frac{G_{i}\left(J_{i} s+D_{i}\right)}{\sum_{m=1}^{n} G_{m}\left(J_{m} s+D_{m}\right)}
$$

where,

$$
G_{i}=\frac{k_{i}}{J_{i} s^{2}+D_{i} s+k_{i}} ;(i=1,2, \cdots n)
$$

$G_{p l i}$ represents the influence of load on the output power of $i^{\text {th }}$ inverter. The output power of paralleled VSG-based inverter is not only related to the load demand and its own parameters, but also affected by the parameters of other inverters.

Analyzing $G_{p l i}$, finding that if the parameters satisfy the following relations that is given by $(20), G_{p l i}$ will become a proportional component, which is equal to $\gamma_{i}$. When load demand changes, the inverter output power changes proportionally without dynamic oscillation process. The conclusion is affirmed by Fig. 3, and (20) can be derived and regarded as a constraint for parameters designed.

$J_{1}: J_{2}: \cdots: J_{n}=D_{1}: D_{2}: \cdots: D_{n}=\frac{1}{X_{1}}: \frac{1}{X_{2}}: \cdots: \frac{1}{X_{n}}=\gamma_{1}: \gamma_{2}: \cdots: \gamma_{n}$

where, $\gamma_{i}$ is a introduced constant and $\sum_{i=1}^{n} \gamma_{i}=1$

The active power control loop in VSG controller is shown in Fig. 4 in details. It includes four parts: PV-VSG, DC-link voltage regulation, battery-VSG and constant power control. They correspond to four different operation states respectively.

PV-VSG is with Part 1, responding to state 1 in TABLE I, in which, $P_{N i}$ represents reference power. In this part, the virtual moment of inertia $J_{P V i}$, damping coefficient $D_{P V i}$ for each PV/ BES-VSG unit are proportional to PV peak power $P_{P V-p p i}$, as shown in (14), $\alpha_{1}, \alpha_{2}$ are constant, and $\alpha_{1}>0, \alpha_{2}>0$.

$$
\frac{J_{P V i}}{P_{P V_{-} p p i}}=\alpha_{1}, \quad \frac{D_{P V i}}{P_{P V_{-} p p i}}=\alpha_{2}
$$

DC-link voltage regulation is with Part 2, responding to state 2 in TABLE I, used for regulating $v_{d c}$, in which, $v_{d c_{-} V S G r e f}$ is the reference voltage.

Battery-VSG is with Part 3, responding to state 3 and 4 in TABLE I. In this part, the virtual moment of inertia $J_{B i}$, damping coefficient $D_{B i}$ for each PV/BES-VSG unit are proportional to the sum of battery charging power limit and discharging power limit, as shown in (15), $\beta_{1}>0, \beta_{2}>0$.

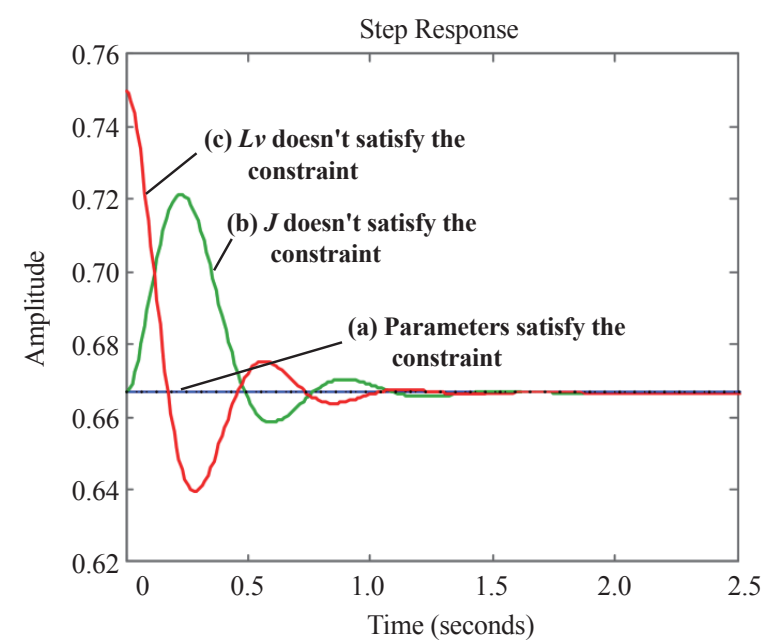

Fig. 3. Step response of $G_{p l i}$ for two VSGs system under different conditions of parameters.

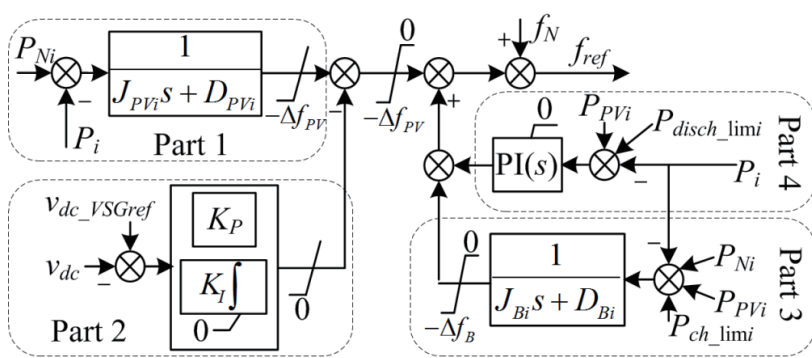

Fig. 4. Control block of active power loop in VSG controller.

$$
\left\{\begin{array}{c}
\frac{J_{B i}}{\left|P_{c h_{-} \lim i}\right|+P_{\text {disch_lim } i}}=\beta_{1} \\
\frac{D_{B i}}{\left|P_{c h \_l i m i}\right|+P_{\text {disch_lim } i}}=\beta_{2}
\end{array}\right.
$$

Taking $i^{\text {th }}$ PV/BES-VSG unit as an example, the power response characteristic of a single VSG is represented by $G_{i}$, as shown in (19).

Then, the natural oscillation frequency $\omega_{n i}$ and damping ratio $\xi_{i}$ are shown in (23).

$$
\left\{\begin{array}{l}
\omega_{n i}=\sqrt{k_{i} / J_{i}} \\
\xi_{i}=0.5 D_{i} / \sqrt{J_{i} k_{i}}
\end{array}\right.
$$

Damping coefficient $D_{P V i}, D_{B i}$ are the slope reciprocal of $f-P$ characteristic curve of inverter,as shown in Fig. 5. Then, virtual inertia $J_{P V i}$, and $J_{B i}$ are designed by considering the overshoot, regulation time of dynamic output power and system stability margin [9]. Meanwhile, the parameters of paralleled inverters should satisfy the constraint conditions shown in (20). When $J_{P V i}, J_{B i}, D_{P V i}$ and $D_{B i}$ are selected, $\alpha_{1}, \alpha_{2}, \beta_{1}, \beta_{2}$ are determined.

Constant power control is with Part 4 , responding to state 5 in TABLE I. At steady state, PI controller adjusts inverter output power to $P_{P V \_M P P T i}+P_{\text {disch_limi }}$. 


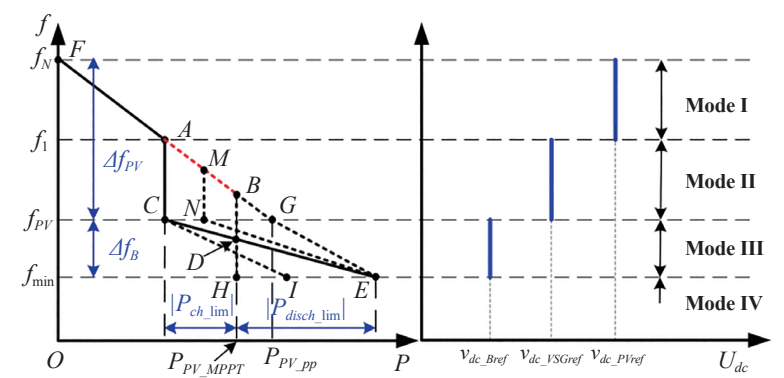

Fig. 5. Output $P-f$ characteristic curve of inverter and DC voltage characteristic curve.

It is important to note that, in Part 3 and 4, the active power reference of the VSG controller is $P_{P V i}$, not $P_{P V-M P P T i}$. When PV/ BES-VSG unit is in state 1 shown in TABLE $\overline{\mathrm{I}}, P_{P V_{-} M P P T i}$ can't be obtained.

\section{B. Control Strategy Analysis}

In order to achieve the expected control objectives, this paper realizes the reasonable combination of different control modes between subsystem controllers by setting reference values and saturation values of the controllers output for each subsystem controller, as shown in Fig. 2 and Fig. 3, reducing the coupling between the subsystem controllers to the greatest extent.

PV/BES-VSG unit has four control modes with different combinations. As mentioned above, when the unit is in state 5, there is no controller to regulate DC-link voltage (corresponding to Mode IV with * in TABLE II), which will lead to the system instability. So the value of $P_{\text {disch _limi }}$ in VSG controller should be smaller than the value obtained by BES Model in BES controller, then the inverter enters into PCM (corresponding to Mode IV with \# in TABLE II). In addition, for the whole microgrid, state 5, which is an overload situation, is an emergency state, $\mathrm{PV} / \mathrm{BES}$ unit should be avoided to enter into Mode IV, which is solved by load control from central controller in EMS, which is beyond the scope of the paper.

Ignoring Mode IV, $f-P$ characteristic curve of inverter with VSG is shown in Fig. 5, the three control modes correspond to the three-segment curves in the frequency range of $\left[f_{N}, f_{\text {min }}\right]$, where $f_{N}$ and $f_{\min }$ define the operating frequency limits of the microgrid. In Fig. 4, point $G$ refers to PV peak power $P_{P V} p$, due to the change of environment conditions, $\mathrm{PV}$ maximum power $P_{P V-M P P T}($ Point $B)$ is usually less than $P_{P V-p p}$.

The frequency range of Line $F G$ is $\left[f_{N}, f_{P V}\right]$, and the droop slope is designed according to (21), where $\alpha_{2}=1 / \Delta f_{P V}$. The frequency range of Line $C E$ is $\left[f_{P V}, f_{B}\right]$, the droop slope is designed according to (22), where $\beta_{2}=1 / \Delta f_{B}$. The projection of Line $C D$ on the horizontal axis refers to battery charging power limit $\mid P_{c h}$ lim $\mid$, the projection of Line $D E$ on the horizontal axis refers to battery discharging power limit $P_{\text {disc_lim. }}$. The sum of $\Delta f_{P V}$ and $\Delta f_{B}$ is maximum frequency deviation of microgrid, which is determined by the power quality standards. In this paper, setting $\Delta f_{P V}$ $=\Delta f_{B}=0.1 \mathrm{~Hz}$, then the maximum frequency deviation of microgrid is equal to $0.2 \mathrm{~Hz}$.

Because PV peak power $P_{P V-p p}$ is the inherent parameter of
TABLE II

PV/BES-VSG Unit Control Mode

\begin{tabular}{|c|c|c|c|c|}
\hline $\begin{array}{l}\text { Control Mode } \\
\text { (VSG Controller) }\end{array}$ & Unit State & $\begin{array}{c}\text { PV } \\
\text { Controller }\end{array}$ & $\begin{array}{c}\text { BES } \\
\text { Controller }\end{array}$ & $\begin{array}{l}\text { DC-link } \\
\text { Voltage }\end{array}$ \\
\hline Mode I & 1 & VCM & PCM & PV \\
\hline Mode II & 2 & MPPT & PCM & VSG \\
\hline \multirow{2}{*}{ Mode III } & 3 & MPPT & VCM & BES \\
\hline & 4 & MPPT & VCM & BES \\
\hline \multirow{2}{*}{ Mode IV } & $5 *$ & MPPT & PCM & \\
\hline & 5 & MPPT & $\mathrm{VCM}$ & BES \\
\hline
\end{tabular}

the microgrid, the droop slope of Line $F G$ will not be affected by the operation conditions (such as temperature and irradiance), while actual operation range changes with PV maximum power and battery charging power. For example, Point $B$ refers to PV maximum power, for $\left|P_{c h \text { lim }}\right|>0$, actual operation point of the inverter is up to Point $A$. The battery charging/discharging power limit is a function of the battery SOC [22], the scope and the projection of Line $C E$ on the horizontal axis change slowly with SOC. Considering battery SOC changing rate is much smaller than the response speed of the controllers, the dynamic change of slope doesn't affect the stability of the microgrid, but optimizes power sharing among the batteries.

Multi-segment operation characteristic, as shown in Fig. 4, is implemented through two steps: 1) multi-segment control of DC-link voltage; 2) set appropriate saturation values of the VSG controllers output.

In Mode I, DC-link voltage is controlled by PV at higher level, battery enters into PCM for the saturation of outer loop, Part 2, 3 and 4 in VSG controller are all ineffective due to saturation, the inverter operates on Line $F A$ in the frequency range of $\left[f_{N}, f_{1}\right]$.

In Mode II, PV works at MPPT, battery remains constant power charging, Part 1 and 2 in VSG controller take effect together, regulating DC-link voltage at middle lever, Part 1, 3 lose effect, the inverter works on Line $A C$ in the frequency range of $\left[f_{1}, f_{P V}\right]$.

In Mode III, PV remains MPPT, DC-link voltage is regulated by battery at lower level, Part 1, 3 and 4 in VSG controller are all ineffective due to saturation, the inverter operates on Line $C E$ in the frequency range of $\left[f_{P V}, f_{\text {min }}\right]$.

The DC-link voltage is divided into three levels, guaranteeing only one controller is used to regulate DC-link voltage. The proposed method avoids relying on the communications between subsystems, and reduces the coupling between subsystems.

When PV maximum power is sufficient, leading to necessary PV curtailment in PV/BES-VSG unit, thus, the DC voltage will be raised and controlled by PV unit. As a result, the DC voltage reference is set at a higher level in the decentralized control strategy in this segment. When PV maximum power is not enough, battery is needed to discharge to increase the output power at DC side, thus, the DC voltage will be reduced and controlled by battery. As a result, the DC voltage reference is set at a lower level in the decentralized control strategy in this segment. When PV maximum power is not enough, battery 
charging power is reduced to keep power balance, thus, the DC voltage will be reduced slightly and controlled by inverter. As a result, the DC voltage reference is set at a middle level in the decentralized control strategy in this segment. Therefore, $v_{d c \_ \text {PVref }}$ $>v_{d c_{-} V S G r e f}>v_{d c_{-} B r e f}$.

The relationship between inverter operation segments and DC-link voltage level is shown in (24).

$$
\begin{aligned}
& v_{d c_{-} r e f}=\left\{\begin{array}{l}
v_{d c_{-} P V r e f}, f \in\left[\begin{array}{ll}
f_{N} & f_{1}
\end{array}\right] \\
v_{d c_{-} \text {VSGref }}, f \in\left[\begin{array}{ll}
f_{1} & f_{P V}
\end{array}\right] \\
v_{d c_{-} B r e f}, f \in\left[\begin{array}{ll}
f_{P V} & f_{\text {min }}
\end{array}\right]
\end{array}\right. \\
& v_{d c_{-} \text {PVref }}>v_{d c_{-} \text {VSGref }}>v_{d c_{-} \text {Bref }}
\end{aligned}
$$

\section{Typical Operation Scenario Analysis}

In this section, typical operation analysis for two scenarios are performed for an islanded microgrid with two PV/BESVSG units shown in Fig. 1, one is for load change, the other is for insolation change or PV maximum output power change.

\section{A. Load Change Scenario}

In this segment, the analysis of operation point shift for the microgrid is performed for load change scenario. At steady state, $f-P$ droop curves of the two PV/BES-VSG units are shown in Fig. 6. At start, Unit1, Unit2 work at point $K_{1}, K_{2}$ respectively, maintaining the microgrid frequency at $f_{1}$ together. With load increasing, Unit1 enters into PCM first. Unit1, Unit2 work at point $M_{1}, M_{2}$ respectively, and the frequency is controlled by Unit2. Then the increased load is totally overtaken by Unit2 until the frequency drops to $f_{3}$. At $f_{3}$, Unit2 also enters into PCM, the output power is limited, and the frequency will drop to $f_{3}$. At $f_{3}$, Unit1 and Unit 2 enter into Mode III, the batteries charging powers reduce by $\Delta P_{1}$ and $\Delta P_{2}$ to keep generation/ consumption balance. The operation points change to $N_{1}, N_{2}$. If the load continues increasing, battery charging powers in each unit reduces proportionally until they reduces to zero (Point $D_{1}$ and $D_{2}$ ). After that, batteries start discharging proportionally to meet the load increases.

\section{B. PV Maximum Output Power Change Scenario}

In this segment, the analysis of operation point shift for the microgrid is performed for PV maximum output power change scenario. Assuming PVs have the same power rating, thus, their $f-P$ droop curves are coincidence. PV maximum output power of one unit is changed. At steady state, their $f-P$ droop curves are shown as Fig. 7.

At start, Unit1, Unit2 operate at point $U, K$ respectively. If PV maximum output power of Unitl is increased from $P_{P V \_M P P T 11}$ (Point $R$ ) to $P_{P V \text { MPPT12 }}$ (Point $S$ ), finally changed to $P_{P V M P P T 13}($ Point $T$ ), then the operation points of Unit1, Unit2 will transition from Point $U$, Point $K$ to $V, M$, then change to $W, N$, the frequency is increased from $f_{a}$ to $f_{b}, f_{c}$.

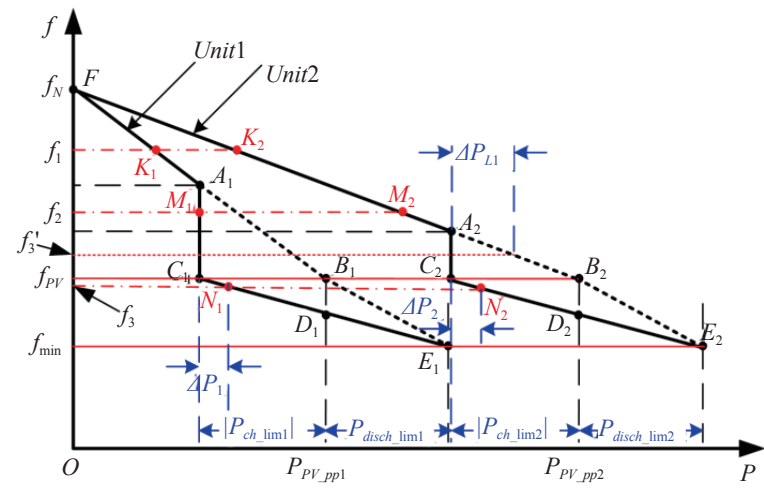

Fig. 6. Load changing operation characteristics.

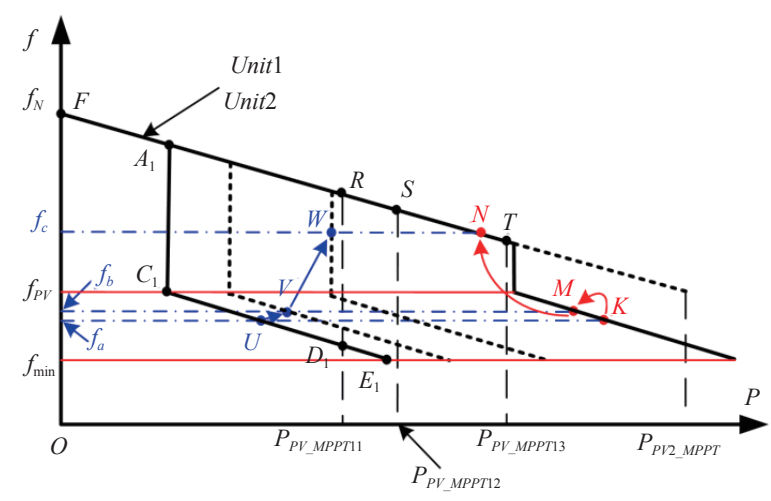

Fig. 7. PV maximum power changing operation characteristics.

\section{Simulation Results and Discussions}

Simulations for load change and PV maximum output power change scenarios are performed and discussed in this section. A detailed model of an islanding microgrid with two PV/Battery-VSG units is built in the Matlab/Simulink to verify the performance of the proposed decentralized coordination control strategy. BES Model is simplified in BES controller, and the battery charging and discharging power limits are set to be constant and the terminal voltage of the battery is set at $300 \mathrm{~V}$.

\section{A. Load Change Scenario}

In this scenario, the main simulation parameters are listed in TABLE III. The simulation results by the proposed control strategy, are illustrated from Fig. 8 to Fig. 11.

The total battery charging power limits is $5 \mathrm{~kW}$, the total maximum PV power is $17.4 \mathrm{~kW}$. Fig. 8 shows the output power profiles of inverters, PVs, batteries responding to the load changes, which is explained as follows.

During $0 \sim 2 \mathrm{~s}$, the load power is equal to $4.5 \mathrm{~kW}$, the total maximum PV power is more than the sum of battery charging power limit and the load demands, the power relationship is shown as in (2). The batteries are charged with their limit powers $2.5 \mathrm{~kW}$. Inverters share load power based on its own PV maximum output power. Unit1 and Unit2 start curtailing the surplus PV power by adjusting their PV array voltage references 
TABLE III

Main System Parameters for Case I

\begin{tabular}{|c|c|c|c|}
\hline Parameter & Value & Parameter & Value \\
\hline Filter inductance & $1 \mathrm{mH}$ & $P_{P V p p 1}$ & $11.6 \mathrm{~kW}$ \\
\hline Filter capacitance & $40 \mathrm{uF}$ & $P_{P V p p 2}$ & $5.8 \mathrm{~kW}$ \\
\hline Line inductance & $0.1 \mathrm{mH}$ & $\left|P_{c h \_l i m 1}\right|$ & $2.5 \mathrm{~kW}$ \\
\hline Switching frequency & $10 \mathrm{kHz}$ & $\left|P_{c h \text { lim } 2}\right|$ & $2.5 \mathrm{~kW}$ \\
\hline$v_{d c_{-} P V r e f}$ & $660 \mathrm{~V}$ & $P_{\text {disch_lim } 1}$ & $5 \mathrm{~kW}$ \\
\hline$v_{d c_{-} \text {VSGref }}$ & $650 \mathrm{~V}$ & $P_{\text {disch_lim2 }}$ & $5 \mathrm{~kW}$ \\
\hline$v_{d c \_B r e f}$ & $640 \mathrm{~V}$ & $J_{P V 1}^{-}$ & 51.2 \\
\hline$\Delta \bar{f}_{P V}$ & $0.1 \mathrm{~Hz}$ & $D_{P V 1}$ & $1.1 \times 10^{5}$ \\
\hline$\Delta f_{B}$ & $0.1 \mathrm{~Hz}$ & $J_{P V 2}$ & 25.6 \\
\hline$f_{N}$ & $50 \mathrm{~Hz}$ & $D_{P V 2}$ & $5.5 \times 10^{4}$ \\
\hline$U_{m}$ & $311 \mathrm{~V}$ & $J_{B 1}$ & 35 \\
\hline$n$ & $2 \times 10^{-4}$ & $D_{B 1}$ & $7.5 \times 10^{4}$ \\
\hline PV temperature & $25^{\circ} \mathrm{C}$ & $J_{B 2}$ & 35 \\
\hline Insolation & $1000 \mathrm{~W} / \mathrm{m}^{2}$ & $D_{B 2}$ & $7.5 \times 10^{4}$ \\
\hline
\end{tabular}

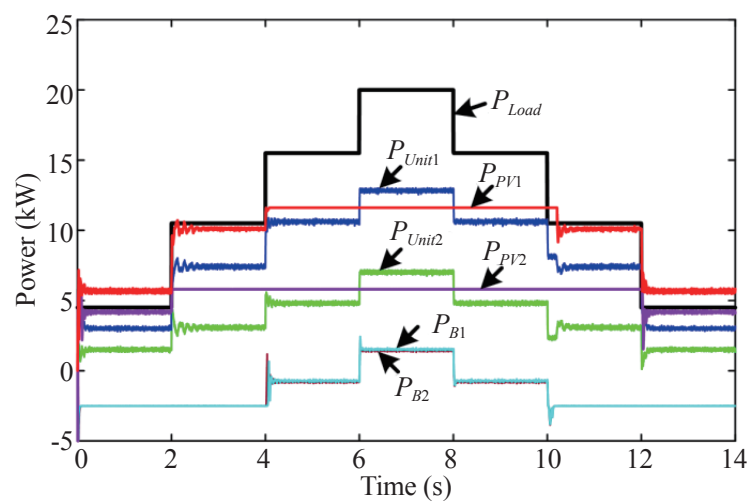

Fig. 8. Output power profiles of units corresponding to changes of loads.

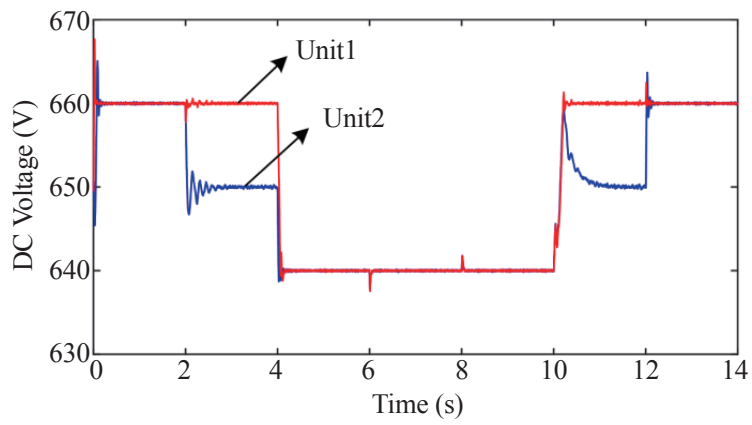

Fig. 9. DC voltages corresponding to changes of loads.

according to the power demand. $P_{\text {Unit } 1}=3 \mathrm{~kW}, P_{\text {Unit } 2}=1.5 \mathrm{~kW}$, $P_{B 1}=P_{B 2}=-2.5 \mathrm{~kW}$ (charging), $P_{P V 1}=5.5 \mathrm{~kW}, P_{P V 2}=4 \mathrm{~kW} . v_{d c}$ is regulated by PV unit, so it is kept at $660 \mathrm{~V}$, as shown in Fig. 9.

During 2 $4 \mathrm{~s}$, load demand is increased to $10.5 \mathrm{~kW}$, the power relationship is shown as (6). The batteries are charged with their limit powers, PV unit in Unit2 starts operating at its maximum PV power, PV unit in Unitl curtails the surplus PV power according to the power demand. $P_{P V 2}=P_{P V M P P T 2}=5.8 \mathrm{~kW}, P_{B 2}=-2.5 \mathrm{~kW}$, $P_{\text {Unit }}=3.3 \mathrm{~kW}, P_{\text {Unit } 1}=7.2 \mathrm{~kW}, P_{B 1}=-2.5 \mathrm{~kW}, P_{P V 1}=9.7 \mathrm{~kW}$. In Unit $1, v_{d c}$ is regulated by PV, so it is kept at $660 \mathrm{~V}$; In Unit2, $v_{d c}$ is regulated by inverter, so it is kept at $650 \mathrm{~V}$, as shown in Fig. 9.

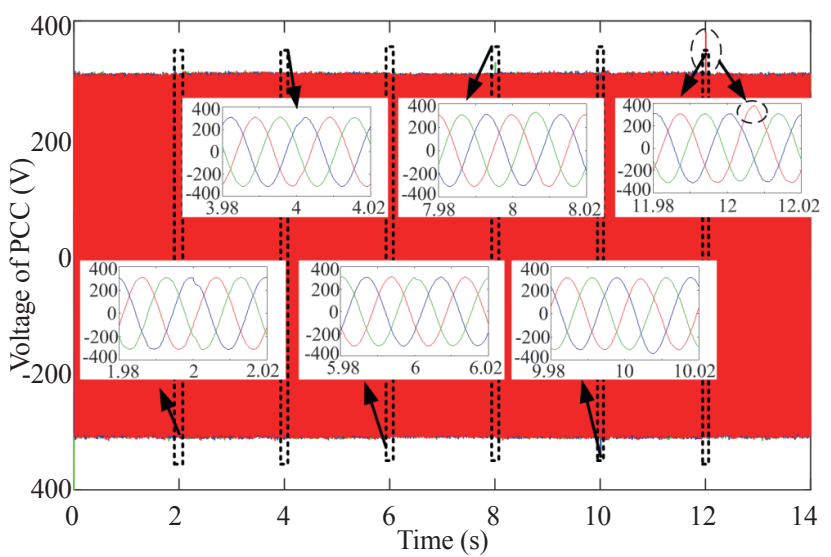

Fig. 10. PCC voltage corresponding to changes of loads.

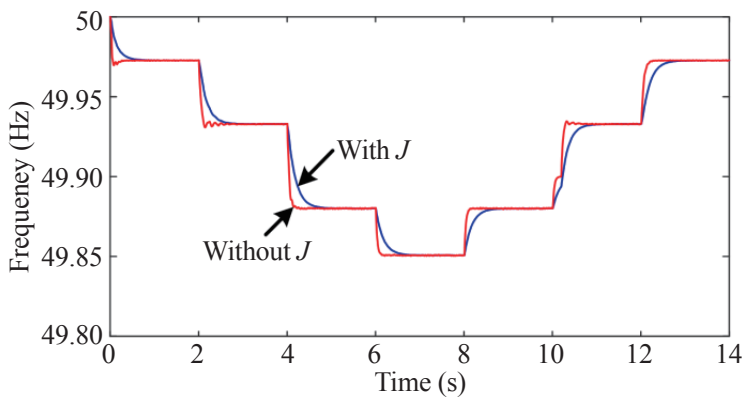

Fig. 11. Frequency of microgrid with and without $J$ corresponding to changes of loads.

During 4 6s, load demand is increased to $15.5 \mathrm{~kW}$, the total maximum PV power is less than the sum of battery charging power limit and the load demands, but the total maximum PV power is more than load demands, the power relationship is shown as (9). PV unit starts working at MPP, $P_{P V 1}=P_{P V M P P T 1}=11.6 \mathrm{~kW}$, $P_{P V 2}=P_{P V M P P T 2}=5.8 \mathrm{~kW}$, but PV power is insufficient to follow the battery charging power limit, thus, the battery charging power decreases with the increased load, $P_{B 1}=P_{B 2}=-0.95 \mathrm{~kW}, P_{\text {Unit } 1}=$ $10.65 \mathrm{~kW}, P_{\text {Unit } 2}=4.85 \mathrm{~kW} . v_{d c}$ is regulated by battery, so it is kept at $640 \mathrm{~V}$, as shown in Fig. 9.

During 6 8s, load demand is increased to $20 \mathrm{~kW}$, the total maximum PV power is less than the load demands, the power relationship is shown as (9). PV unit starts working at MPP, $P_{P V 1}$ $=11.6 \mathrm{~kW}, P_{P V 2}=5.8 \mathrm{~kW}$. PV power is insufficient to supply the load, thus, the battery begins to discharge power with the increased load, $P_{B 1}=P_{B 2}=1.3 \mathrm{~kW}, P_{\text {Unit } 1}=12.9 \mathrm{~kW}, P_{\text {Unit }}=7.1 \mathrm{~kW}$. $v_{d c}$ is regulated by battery, so it is kept at $640 \mathrm{~V}$, as shown in Fig. 9.

The following simulation conditions are symmetrical with the conditions above after $\mathrm{t}=7 \mathrm{~s}$.

The simulation conditions above cover all the possible operation modes for the islanded microgrid with two PV/BESVSG units. The DC-link voltage and the voltage at PCC of the microgrid are also the same as expected, as shown in Fig. 9 and Fig. 10. In different operation modes, DC-link voltage $v_{d c}$ is controlled by different units, therefore, it has different values. The simulation results demonstrate that the control system works well by the proposed method when the operation points 
shift because of variation of loads.

Fig. 11 shows the results for two scenarios with and without virtual inertia J. It can be found that VSG can reduce the rate of change of frequency, thus improve the frequency stability of the microgrid.

\section{B. PV Maximum Output Power Change Scenario}

In this section, the main simulation parameters are listed in TABLE IV, other parameters are as the same as parameters in case I. The simulation results by the proposed method are illustrated from Fig. 12 to Fig. 15, in which the load power is kept at $15 \mathrm{~kW}$.

Fig. 12 shows the output power profiles of inverters, PVs, batteries responding to the insolation changes, which are explained in detail as follows.

During 0 2s, the insolation of PV1 and PV2 are both $1000 \mathrm{~W} / \mathrm{m}^{2}$, the maximum power of PV1, PV2 are both $11.6 \mathrm{~kW}$. The total maximum PV power is more than the sum of battery charging power limit and the load demands, the power relationship is shown as (2). The batteries are charged with their limit powers $2.5 \mathrm{~kW}$. Inverters share load power equally. PV1 and PV2 start curtailing the surplus PV power by adjusting their PV array voltage references according to the power demand. $P_{\text {Unit } 1}=P_{\text {Uni } 2}=7.5 \mathrm{~kW}$, $P_{B 1}=P_{B 2}=-2.5 \mathrm{~kW}$ (charging), $P_{P V 1}=P_{P V 2}=10 \mathrm{~kW} . v_{d c}$ is regulated by PV unit, so it is kept at $660 \mathrm{~V}$, as shown in Fig. 13.

During 2 4s, the insolation of PV2 changes to $776 \mathrm{~W} / \mathrm{m}^{2}$, the maximum power of PV1 is kept at $11.6 \mathrm{~kW}$, the maximum power of PV2 is reduced to $9 \mathrm{~kW}$ due to the decline of insolation, the power relationship is shown as (6). The batteries are charged with their limit powers, PV2 starts operating at its maximum PV power, PV1 curtails the surplus PV power according to the power demand. $P_{P V 2}=P_{P V M P P T 2}=9 \mathrm{~kW}, P_{B 2}=-2.5 \mathrm{~kW}$, $P_{\text {Unit } 2}=6.5 \mathrm{~kW}, P_{\text {Unit } 1}=8.5 \mathrm{~kW}, P_{B 1}=-2.5 \mathrm{~kW}, P_{P V 1}=11 \mathrm{~kW}$. In Unit $1, v_{d c}$ is regulated by PV, so it is kept at $660 \mathrm{~V}$. In Unit2, $v_{d c}$ is regulated by inverter, so it is kept at $650 \mathrm{~V}$, as shown in Fig. 13.

During $4 \sim 6 \mathrm{~s}$, the insolation of PV2 changes to $600 \mathrm{~W} / \mathrm{m}^{2}$, the maximum power of PV1 is kept at $11.6 \mathrm{~kW}$, the maximum power of PV2 is reduced to $7 \mathrm{~kW}$ due to the drop of irradiation. The total maximum PV power is less than the sum of battery charging power limit and the load demands, but the total maximum PV power is more than load demands, the power relationship is shown as (9). PVs start to work at MPP, $P_{P V 1}=$ $P_{P V \_M P P T 1}=11.6 \mathrm{~kW}, P_{P V 2}=P_{P V_{-} M P P T 2}=7 \mathrm{~kW}$, but PV power is in sufficient to follow the battery charging power limit, so the battery charging power decreases with the increased load, $P_{B 1}=$ $P_{B 2}=-1.8 \mathrm{~kW}, P_{\text {Unit } 1}=9.8 \mathrm{~kW}, P_{\text {Unit } 2}=5.2 \mathrm{~kW} . v_{d c}$ is regulated by battery, so it is kept at $640 \mathrm{~V}$, as shown in Fig. 13.

During $6 \sim 8 \mathrm{~s}$, the maximum power of PV2 is kept at $7 \mathrm{~kW}$, the insolation of PV2 changes to $520 \mathrm{~W} / \mathrm{m}^{2}$, the maximum power of PV1 is reduced to $6 \mathrm{~kW}$ due to the drop of irradiation. The total maximum PV power is less than the load demands and the power relationship is shown as (9). PVs start working at MPP, $P_{P V 1}=6 \mathrm{~kW}, P_{P V 2}=7 \mathrm{~kW}$. PV power is insufficient to supply the load, so the battery begins to discharge power with the increased load, $P_{B 1}=P_{B 2}=1 \mathrm{~kW}, P_{\text {Unit } 1}=7 \mathrm{~kW}, P_{\text {Unit } 2}=8 \mathrm{~kW}$. $v_{d c}$ is regulated by battery, so it is kept at $640 \mathrm{~V}$, as shown in Fig. 13.
TABLE IV

Main System Parameters for CAse II

\begin{tabular}{cccc}
\hline \hline Parameter & Value & Parameter & Value \\
\hline$P_{P V \_p 1}$ & $11.6 \mathrm{~kW}$ & $D_{P V 1}$ & $1.1 \times 10^{5}$ \\
$P_{P V \_p 2}$ & $11.6 \mathrm{~kW}$ & $J_{P V 2}$ & 51.2 \\
$\left|P_{c h \_l i m 1}\right|$ & $2.5 \mathrm{~kW}$ & $D_{P V 2}$ & $1.1 \times 10^{5}$ \\
$\left|P_{\text {ch_lim } 2}\right|$ & $2.5 \mathrm{~kW}$ & $J_{B 1}$ & 35 \\
$P_{\text {disch_lim } 1}$ & $5 \mathrm{~kW}$ & $D_{B 1}$ & $7.5 \times 10^{4}$ \\
$P_{\text {disch_lim2 } 2}$ & $5 \mathrm{~kW}$ & $J_{B 2}$ & 35 \\
$J_{P V 1}$ & 51.2 & $D_{B 2}$ & $7.5 \times 10^{4}$ \\
\hline \hline
\end{tabular}

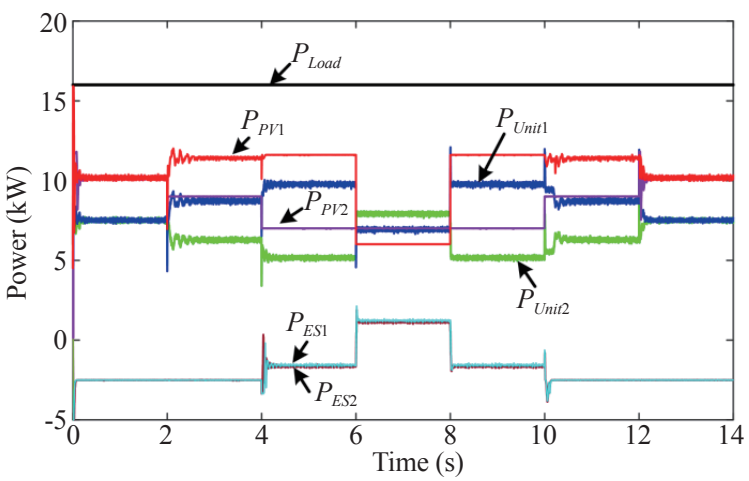

Fig. 12. Output powers of each unit corresponding to changes of insolation.

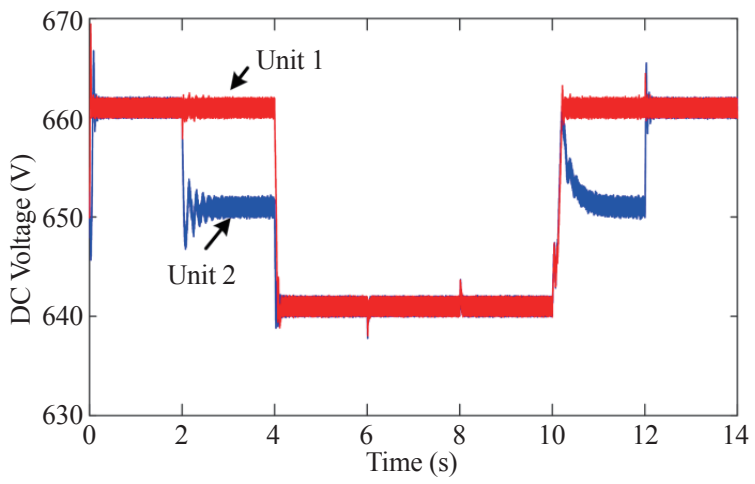

Fig. 13. DC voltages corresponding to changes of insolation.

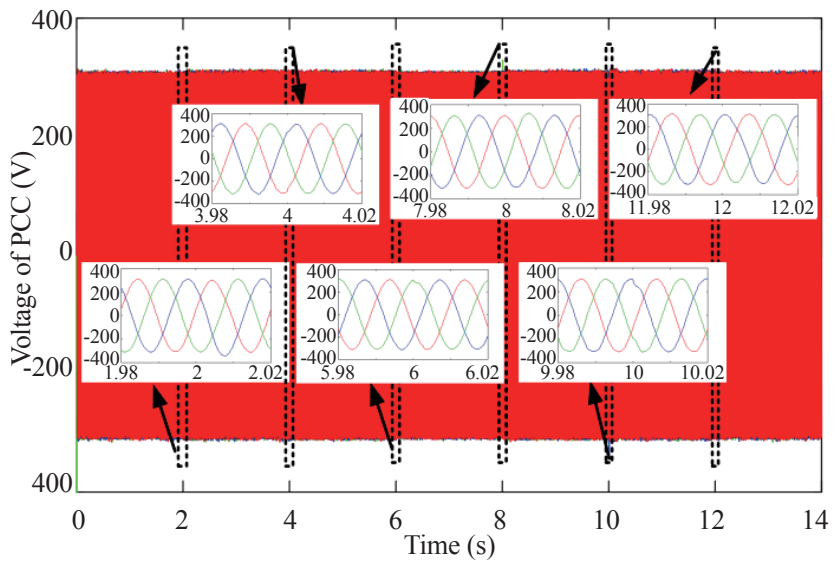

Fig. 14. PCC voltage corresponding to changes of insolation. 


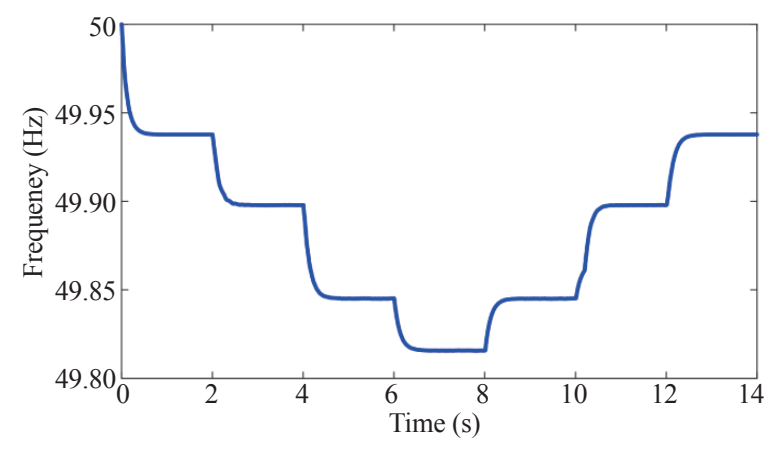

Fig. 15. Frequency of microgrid corresponding to changes of insolation.

The following simulation conditions are symmetrical with the conditions above after $\mathrm{t}=7 \mathrm{~s}$.

Fig. 14 shows the voltage at PCC, Fig. 15 shows frequency of microgrid. From Fig. 14 and Fig. 15, it can be seen that the voltage and frequency of the microgrids can be kept as stable as expected by the proposed method when the operation points shift with variation of $\mathrm{PV}$ maximum output power.

\section{Conclusions}

In this paper, a decentralized coordination control method is proposed for load sharing in paralleled inverters with $\mathrm{PV} /$ battery-VSG units. The whole system can operate in five states according to the relationship between the load, the total PV maximum output power, the total battery charging, discharging power limits. The operation of PV/BES-VSG unit has four modes. In different modes, the subsystems (PV Controller, Battery Controller, VSG Controller) have different control objectives.

With the proposed method, the droop characteristics of VSGs can be adaptively adjusted according to the DC bus voltage and frequency of the microgrid because local controllers for each PV/Battery-VSG unit are able to switch operating modes automatically.

The simulation results for an islanding microgrid with two PV/BES-VSG units verify that the batteries supply power only when all PV units reach their limits to prolong the battery life, otherwise, the batteries keep charging, therefore the proposed method can maximize the use of PV and ensure the reasonable power sharing between inverters while improving the frequency stability of the microgrid. The proposed method is also applicable to multiple PV/BES-VSG units more than two.

\section{REFERENCES}

[1] International Energy Agency, “World Energy Outlook 2017," IEA, vol. Chapter 1, Dec. 2017.

[2] E. Kabir, P. Kumar, S. Kumar, A. A. Adelodun, and K. H. Kim, "Solarenergy: Potential and future prospects,"Renewable \& Sustainable Energy Reviews, vol. 82, pp. 894-900, Feb. 2018.

[3] B. Wang. Development of Photovoltaic Industry in China--Review of 2017 and Prospect of 2018.[Online]. Available:http://www.sohu.com/ a/218597826_99917533(in Chinese).

[4] P. Sindhuja and U. V. Reddy, "Enhancement of grid connected PV inverter using optimal maximum power point tracking algorithm with estimation of climatic parameter," in 2017 International Conference
onInventive Systems and Control (ICISC), Seoul, Korea, 2017, pp. 1-6.

[5] M. Liserre, T. Sauter, and Y. J. Hung, "Future energy systems: Integrating renewable energy sources into the smart power grid through industrial electronics," IEEE Industrial Electronics Magazine, vol. 4, no. 1, pp. 18-37, Mar. 2010.

[6] H. Bevrani, T. Ise, Y. Miura, "Virtual synchronous generators: A survey and new perspectives,"International Journal of Electrical Power \& Energy Systems, vol. 54, no. 1, pp. 244-254, Jan. 2014.

[7] J. Liu, Y. Miura, H. Bevrani, and T. Ise, "Enhanced virtual synchronous generator control for parallel inverters in microgrids," IEEE Transactions on Smart Grid, vol. 8, no. 5. pp. 2268-2277, Feb. 2016.

[8] Q. C. Zhong, "Virtual synchronous machines: A unified interface for grid integration," IEEE Power Electronics Magazine, vol. 3, no. 4. pp. 18-27, Dec. 2016

[9] J. Alipoor, Y. Miura, and T. Ise, "Power system stabilization using virtual synchronous generator with alternating moment of inertia," IEEE Journal of Emerging \& Selected Topics in Power Electronics, vol. 3, no. 2, pp. 451-458, Jun. 2016.

[10] H. Xu, X. Zhang, F. Liu and F. Mao, "An improved virtual synchronous generator algorithm for system stability enhancement," in $\mathrm{Fu}$ ture Energy Electronics Conference, IEEE, Taipei, Taiwan, 2015, pp. $1-6$.

[11] S. D'Arco, J. A. Suul, and O. B. Fosso, "A virtual synchronous machine implementation for distributed control of power converters in SmartGrids, "Electric Power Systems Research, vol. 122, no. 6, pp. 180-197, May 2015.

[12] H. H. Hamid and A. I. H. Ahmed, "Power sharing for inverters based on virtual synchronous generator control," Indonesian Journal of Electrical Engineering and Computer Science, vol. 2, no. 2, pp. 305314, May 2016.

[13] T. Zheng, L. Chen, W. Liu, Y. Guo, and S. Mei, "Multi-mode operation control for photovoltaic virtual synchronous generator considering the dynamic characteristics of primary source," Proceedings of the CSEE, vol. 37, no. 2, pp. 454-463, Jan. 2017 (in Chinese).

[14] N. L. Díaz, A. C. Luna, J. C.Vasquez and J. M. Guerrero, "Centralized control architecture for coordination of distributed renewable generation and energy storage in islanded AC microgrids," IEEE Transactions on Power Electronics, vol. 32, no. 7, pp. 5202-5213, Jul. 2017.

[15] M. A. Roslan, S. A. Azmi, B. Ismail, M. M. Azizan, and S. S. Lee, "Centralize control power sharing scheme of parallel connected inverters for microgrids," in IEEE International Conference on Power and Energy, IEEE, Melaka, Malaysia, 2017, pp. 692-696.

[16] D. Wu, F. Tang, T. Dragicevic, J. C. Vasquez, J. M. Guerrero, “A control architecture to coordinate renewable energy sources and energy storage systems in islanded microgrids," IEEE Transactions on Smart Grid, vol. 6, no. 3. pp. 1156-1166, May 2015.

[17] Y. Karimi, H. Oraee, M. S. Golsorkhil, and J. M. Guerrero, "Decentralized method for load sharing and power management in a PV/Battery hybrid source islanded microgrid," IEEE Transactions on Power Electronics, vol. 32, no. 5, pp. 3525-3535, May 2017.

[18] D. Wu, F. Tang, T. Dragicevic, J. C. Vasquez, and J. M. Guerrero, "Autonomous active power control for islanded AC microgrids with photovoltaic generation and energy storage system," IEEE Transactions on Energy Conversion, vol. 29, no. 4, pp. 882-892, Dec. 2014.

[19] H. Mahmood and J. Jiang, "Autonomous coordination of multiple PV/ Battery hybrid units in islanded microgrids," IEEE Transactions on Smart Grid, vol. 99, pp. 1-10, May 2017.

[20] P. Sreekumar and V. Khadkikar, "Adaptive power management strategy for effective volt-ampere utilization of a photovoltaic generation unit in standalone microgrids," IEEE Transactions on Industry Applications, vol. 54, no. 2, pp. 1784 -1792, Apr. 2018.

[21] N. Korada and M. K. Mishra, "Grid adaptive power management strategy for an integrated microgrid with hybrid energy storage," IEEE Transactions on Industrial Electronics, vol. 64, no. 4, pp. 28842892, Apr. 2017.

[22] H. Mahmood, D. Michaelson, and J. Jiang, "Strategies for independent deployment and autonomous control of PV and battery units in islanded microgrids," IEEE Journal of Emerging \& Selected Topics in Power Electronics, vol. 3, no. 3, pp. 742-755, Sep. 2015.

[23] X. Yan, Y. Cheng, T. Deng, W. Zhang, and T. Hua, "Dynamic power distribution strategy based on virtual rotor excitation characteristic 
and stator impedance," in Power Electronics and Motion Control Conference, IEEE, Hefei, China, 2016, pp. 1964-1968.

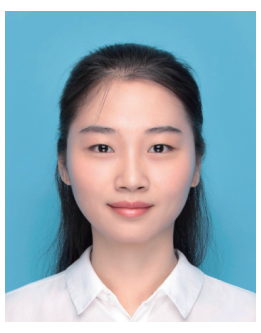

Cheng Qian received the B.Sc. degree in electrical engineering and automation from Shanghai University of Technology, Shanghai, China, in 2015.She is currently pursuing the M.Sc. degree in electrical engineering at Hefei University of Technology, Hefei, China. Her research interests include virtual synchronous generator control strategy, distributed power generation.

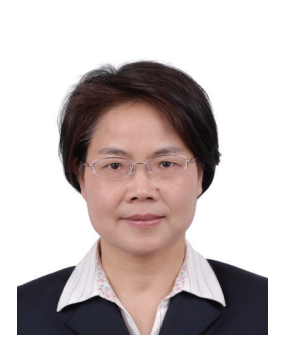

Meiqin Mao received the B.Sc., M.Sc. and Ph.D. degree in electrical engineering from Hefei University of Technology in 1983, 1988 and 2004 respectively. She is now a Professor with School of Electrical and Automation Engineering, Hefei University of Technology (HFUT) China. And her research interests include renewable energy generation technology, distributed power generation and microgrids, power electronics and electric motors.

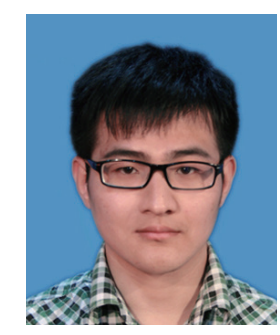

Yong Ding received the B.Sc. degree in electrical engineering \& Its Automation from Shenyang University of Chemical Technology, Liaoning, China, in 2013, the M.Sc. degree in power electronics and drive from the Hefei University of Technology, Anhui, China, in 2015. He is currently pursuing the $\mathrm{Ph} . \mathrm{D}$. degree in electrical engineering at Hefei University of Technology, Hefei, China. His research interests include renewable energy generation technology, EV integration into grid and microgrids. 